\title{
Corticosteroid tapering with benralizumab treatment for eosinophilic asthma: PONENTE Trial
}

\author{
Andrew Menzies-Gow ${ }^{1}$, Jonathan Corren ${ }^{2,3}$, Elisabeth H. Bel ${ }^{4}$, Jorge Maspero ${ }^{5}$, \\ Liam G. Heaney ${ }^{6}$, Mark Gurnell7, Peter Wessman ${ }^{8}$, Ubaldo J. Martin (1)?, \\ Shahid Siddiqui ${ }^{\prime}$ and Esther Garcia Gil ${ }^{10}$
}

Affiliations: ${ }^{1}$ Royal Brompton Hospital, London, UK. ${ }^{2}$ Depts of Medicine and Pediatrics, David Geffen School of Medicine at UCLA, Los Angeles, CA, USA. ${ }^{3}$ Allergy Medical Clinic, Los Angeles, CA, USA. ${ }^{4}$ Academic Medical Centre, University of Amsterdam. Amsterdam, The Netherlands. ${ }^{5}$ Fudación CIDEA, Buenos Aires, Argentina. ${ }^{6}$ Queen's University Belfast, Belfast, UK. ${ }^{7}$ Wellcome Trust-MRC Institute of Metabolic Science, University of Cambridge, Cambridge, UK. ${ }^{8}$ AstraZeneca, Gothenburg, Sweden. ${ }^{9}$ AstraZeneca, Gaithersburg, MD, USA.

${ }^{10}$ AstraZeneca, Barcelona, Spain.

Correspondence: Andrew Menzies-Gow, Royal Brompton Hospital, Sydney Street, London, SW3 6NP, UK. E-mail: a.menzies-gowarbht.nhs.uk

ABSTRACT Benralizumab is an interleukin-5 receptor $\alpha$-directed cytolytic monoclonal antibody approved in several countries for the add-on maintenance treatment of patients with severe eosinophilic asthma aged 12 years and older. In the 28-week Phase III ZONDA trial (ClinicalTrials.gov identifier: NCT02075255), benralizumab produced a median 75\% reduction from baseline in oral corticosteroid (OCS) dosage (versus 25\% for placebo) while maintaining asthma control for patients with OCSdependent severe asthma. This manuscript presents the detailed protocol for the Phase IIIb PONENTE (ClinicalTrials.gov identifier: NCT03557307), a study that will build on the findings from ZONDA.

As the largest steroid-sparing study undertaken in severe asthma, PONENTE has a faster steroid tapering schedule for prednisone dosages $\geqslant 7.5 \mathrm{mg} \cdot \mathrm{day}^{-1}$ than previous studies, and it includes an evaluation of adrenal insufficiency and an algorithm to taper OCS dosage when prednisone dosage is $\leqslant 5 \mathrm{mg} \cdot \mathrm{day}^{-1}$. It also has a longer maintenance phase to assess asthma control for up to 6 months after completion of OCS tapering.

The two primary endpoints are whether patients achieve $100 \%$ reduction in daily OCS use and whether patients achieve $100 \%$ reduction in daily OCS or achieve OCS dosage $\leqslant 5 \mathrm{mg} \cdot \mathrm{day}^{-1}$, if adrenal insufficiency prevented further reduction, both sustained over $\geqslant 4$ weeks without worsening of asthma. Safety and change from baseline in health-related quality of life will also be assessed.

PONENTE should provide valuable guidance for clinicians on tapering OCS dosage, including the management of adrenal insufficiency, following benralizumab initiation for the treatment of patients who are OCS-dependent with severe, uncontrolled eosinophilic asthma.

@ERSpublications

PONENTE will provide valuable guidance for clinicians on tapering oral corticosteroid dosage, including management of adrenal insufficiency, following benralizumab initiation for the treatment of patients with severe, uncontrolled eosinophilic asthma http://bit.ly/2JddVkf

Cite this article as: Menzies-Gow A, Corren J, Bel EH, et al. Corticosteroid tapering with benralizumab treatment for eosinophilic asthma: PONENTE Trial. ERJ Open Res 2019; 5: 00009-2019 [https://doi.org/10.1183/23120541.00009-2019].

This article has supplementary material available from openres.ersjournals.com

This study is registered at www.clinicaltrials.gov with identifier number NCT03557307. Data underlying the findings described in this manuscript may be requested in accordance with AstraZeneca's data-sharing policy described at https://astrazenecagroup-dt.pharmacm.com/DT/Home.

Received: 09 Jan 2019 | Accepted after revision: 21 June 2019

Copyright $\odot$ ERS 2019. This article is open access and distributed under the terms of the Creative Commons Attribution Non-Commercial Licence 4.0. 


\section{Introduction}

Asthma is a chronic disease that affects more than 339 million people worldwide [1]. It is associated with airway inflammation and hyperresponsiveness, together with reversible airway obstruction [2, 3]. Approximately $10 \%$ of patients with asthma have severe disease, defined by international guidelines (Global Initiative for Asthma (GINA)/European Respiratory Society/American Thoracic Society) as disease that requires treatment with high-dosage inhaled corticosteroids (ICSs) plus bronchodilators with or without oral corticosteroids (OCSs) to control symptoms, or disease that remains uncontrolled despite this treatment [3, 4]. In different studies, $44-87 \%$ of patients with severe asthma are estimated to have uncontrolled disease (GINA classification or similar) [4]. These patients experience poor symptom control, frequent severe and potentially life-threatening exacerbations or fixed airflow obstruction, symptoms which can have devastating impacts on health-related quality of life (HRQOL) [3, 5].

OCSs are used to treat asthma exacerbations and as maintenance treatment for patients with severe, uncontrolled eosinophilic asthma at risk of repeated severe exacerbations [3, 6]. Of patients with severe asthma, an estimated $32-45 \%$ rely on recurrent or maintenance OCS use [7,8]. Not only does long-term OCS use have substantial consequences, but cumulative dosing from recurrent OCS use in the shorter term is also associated with adverse events (AEs) including osteoporosis, fractures, hyperglycaemia, diabetes, cardiovascular disease, anxiety and immunosuppression $[5,6,9,10]$. Furthermore, long-term OCS use can suppress the hypothalamic-pituitary-adrenal (HPA) axis, occasionally resulting in adrenal insufficiency (AI) $[11,12]$. These AEs have a further negative impact on the HRQOL of patients with severe asthma and can also worsen other comorbidities.

Benralizumab is an interleukin-5 receptor $\alpha$-directed cytolytic monoclonal antibody that induces direct, rapid and nearly complete depletion of eosinophils via enhanced antibody-dependent cell-mediated cytotoxicity $[13,14]$. Benralizumab is approved in several countries, including the United States, where it is indicated for the add-on maintenance treatment of patients with severe eosinophilic asthma aged 12 years and older [15]. In the Phase III SIROCCO (ClinicalTrials.gov identifier: NCT01928771) and CALIMA (ClinicalTrials.gov identifier: NCT01914757) trials, benralizumab in combination with high-dosage ICSs plus long-acting $\beta_{2}$-agonists (LABAs) significantly reduced asthma exacerbations and improved lung function and disease control for patients with severe, uncontrolled asthma and blood eosinophil counts $\geqslant 300$ cells $\mu \mathrm{L}^{-1}$ versus placebo $[16,17]$.

In the Phase III ZONDA trial (ClinicalTrials.gov identifier: NCT02075255), OCS dosage was reduced with benralizumab treatment from baseline to Week 28 by a median of $75 \%$ compared with a $25 \%$ reduction for placebo [18]. Of patients eligible for a $100 \%$ reduction in OCS dosage (who were receiving $\leqslant 12.5 \mathrm{mg}$ of prednisone per day at baseline), $52 \%$ and $56 \%$ of patients receiving benralizumab every 4 weeks (Q4W) and every 8 weeks (Q8W; first three doses Q4W), respectively, had a 100\% reduction in their OCS dosage by Week 28 compared with a 19\% reduction for placebo [18]. However, because of the relatively short OCS tapering timeline in ZONDA (28 weeks), the potential for down-titration for patients receiving baseline prednisone $>12.5 \mathrm{mg} \cdot \mathrm{day}^{-1}$ was not fully studied. The PONENTE trial (ClinicalTrials.gov identifier: NCT03557307) builds on ZONDA and other OCS-sparing studies. PONENTE is a Phase IIIb trial designed to evaluate the efficacy and safety of tapering OCS use after initiation of benralizumab treatment for adult patients with severe, uncontrolled asthma with eosinophilic inflammation. PONENTE has a faster steroid tapering schedule for prednisone dosages $\geqslant 7.5 \mathrm{mg} \cdot$ day $^{-1}$ (when patients are not at risk of AI) than previous studies, and it includes an evaluation of $\mathrm{AI}$ and an algorithm to specifically taper OCS dosage when prednisone is $\leqslant 5 \mathrm{mg} \cdot \mathrm{day}^{-1}$, and when patients are potentially at risk of developing AI. It also has a longer maintenance phase to assess the ability to maintain the achieved OCS reduction and the impact of OCS reduction on asthma control for up to 6 months after reduction and completion of OCS tapering. In this manuscript, we describe the PONENTE protocol in detail, including the steroid-tapering schedule.

\section{Study methodology}

PONENTE is an ongoing multicentre, open-label, Phase IIIb study that aims to enrol 600 patients in approximately 180 clinical centres worldwide. Participating countries include Argentina, Belgium, Brazil, Canada, Colombia, Denmark, France, Germany, Italy, Mexico, Poland, Russian Federation, Spain, Sweden, Taiwan, United Kingdom and the United States. The PONENTE study design and future implementation are guided by an expert scientific committee that, in addition to respiratory disease clinical experts, includes an endocrinologist. The trial began enrolling on August 1, 2018, with a planned study completion projected or approximately in October 2020.

\section{Study participants}

Eligible patients are men and women aged $\geqslant 18$ years with physician-diagnosed asthma requiring high-dosage ICS (fluticasone propionate or equivalent $>500 \mu \mathrm{g} \cdot$ day $^{-1}$ ) plus LABA for $\geqslant 6$ months before 


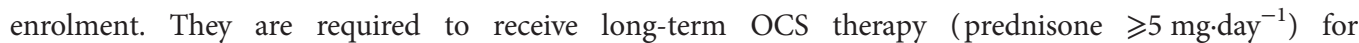
$\geqslant 3$ continuous months and a stable OCS dosage for $\geqslant 4$ weeks before enrolment. Alternate OCS dosing (e.g. every other day), other dosing frequencies, and OCS therapy other than prednisone/prednisolone are allowed provided the average daily dose is equivalent to $\geqslant 5 \mathrm{mg}$ of prednisone and the patient is switched to daily prednisone/prednisolone at Visit 1. Prednisone/prednisolone was selected because it is the most common OCS used in clinical practice. Patients must also have documented blood eosinophil counts $\geqslant 150$ cells $\mu \mathrm{L}^{-1}$ at enrolment or $\geqslant 300$ cells $\mu \mathrm{L}^{-1}$ in the 12 months before enrolment.

Patients will be excluded if they have any current, clinically important pulmonary disease other than asthma or a previous diagnosis for a pulmonary or systemic disease other than asthma that is associated with elevated peripheral blood eosinophil counts. Patients receiving any of the following treatments within 30 days will not be eligible for inclusion: macrolides, antivirals, azole therapies, immunosuppressants, blood products, immunoglobulin, live attenuated vaccines, and lipoxygenase inhibitors. They will also be excluded if they have any comorbidities requiring OCS treatment. Full inclusion and exclusion criteria are included in the appendix. Patients will be allowed to continue their usual asthma controller medication during the study.

Independent ethics committees at each study centre will approve the clinical study protocol. The national regulatory authorities have approved the clinical study protocol or received a notification per local regulations. All patients will be required to provide written informed consent before participation. The study will be conducted in accordance with the principles of the Declaration of Helsinki, which is consistent with the International Conference on Harmonisation/Good Clinical Practice, as well as applicable regulatory requirements and AstraZeneca company policy on bioethics and human biologic samples.

\section{Study design}

PONENTE consists of an enrolment period and an open-label treatment period (figure 1). During the enrolment period, patients who are receiving OCS other than prednisone/prednisolone will be switched to this treatment. The open-label benralizumab treatment period consists of a 4-week induction phase, a variable OCS tapering phase, and a 24-32-week maintenance phase. No adjustments to OCS dosage are permitted during the 4 -week induction phase.

\section{Treatment}

Starting at Week 0, patients will receive benralizumab $30 \mathrm{mg}$ by subcutaneous injection Q4W for the first three doses and Q8W thereafter. Patients will receive benralizumab at the first induction phase visit and throughout the induction phase, OCS tapering phase, and maintenance phase. Patients will continue their baseline ICS plus LABA maintenance therapy during the study.

\section{Oral corticosteroid tapering protocol}

The OCS tapering phase will begin at Week 4. During this phase, OCS dosages will be reduced by $5 \mathrm{mg}$ either weekly or every 2 weeks (Q2W) or by $2.5 \mathrm{mg}$ Q2W or Q4W, depending on the baseline OCS dosage, until a dosage of $5 \mathrm{mg} \cdot \mathrm{day}^{-1}$ is achieved (figure 2). The speed of OCS tapering will also depend on the patient's degree of asthma control, as assessed by the investigator, based on patient-reported symptom information, weekly Asthma Control Questionnaire 6 (ACQ-6) scores, compliance with maintenance asthma therapy, and occurrence of an asthma exacerbation. For prednisone dosages $<5 \mathrm{mg} \cdot \mathrm{day}^{-1}$, if the exact dosage is unavailable, daily dosage can be achieved by dosing every other day, where the daily dosage is the average of 2 days.

For patients who reduce to OCS dosages of $5 \mathrm{mg} \cdot \mathrm{day}^{-1}$, a HPA axis integrity evaluation for AI will be performed after 4 weeks at this dosage (figure 3). For patients receiving an OCS dosage of $5 \mathrm{mg} \cdot$ day $^{-1}$ at baseline, HPA axis integrity evaluation will be performed 4 weeks after the first dose of benralizumab, prior to the OCS reduction phase. The HPA axis integrity evaluation will consist of a morning (between 8 and $9 \mathrm{am}$ ) serum cortisol concentration measurement $24 \mathrm{~h}$ after the last OCS dose and at least $12 \mathrm{~h}$ after the last ICS dose. An adrenocorticotropic hormone (ACTH) stimulation test (i.e. Synacthen ${ }^{\circ}$, Cortrosyn ${ }^{\mathrm{TM}}$ ) will be performed within 1 week of morning cortisol test results for patients with cortisol concentrations indicating partial AI (range, $100-350 \mathrm{nmol} \cdot \mathrm{L}^{-1}$; normal concentration $>350 \mathrm{nmol} \cdot \mathrm{L}^{-1}$; complete AI concentration $\left.<100 \mathrm{nmol} \cdot \mathrm{L}^{-1}\right)$. Patients will be required to withhold OCS use for $\geqslant 24 \mathrm{~h}$ before testing and withhold ICS/LABA use on the morning of testing. Patients will receive an intravenous injection of tetracosactide $250 \mu \mathrm{g}$, with serum cortisol concentrations measured before and $30 \mathrm{~min}$ after injection (further details of the ACTH testing procedure are provided in the appendix). For ACTH testing, a cortisol concentration $>450 \mathrm{nmol} \cdot \mathrm{L}^{-1}$ will be considered normal, and concentrations $250-450 \mathrm{nmol} \cdot \mathrm{L}^{-1}$ and $<250 \mathrm{nmol} \cdot \mathrm{L}^{-1}$ will be considered partial and complete AI, respectively. For patients without evidence 


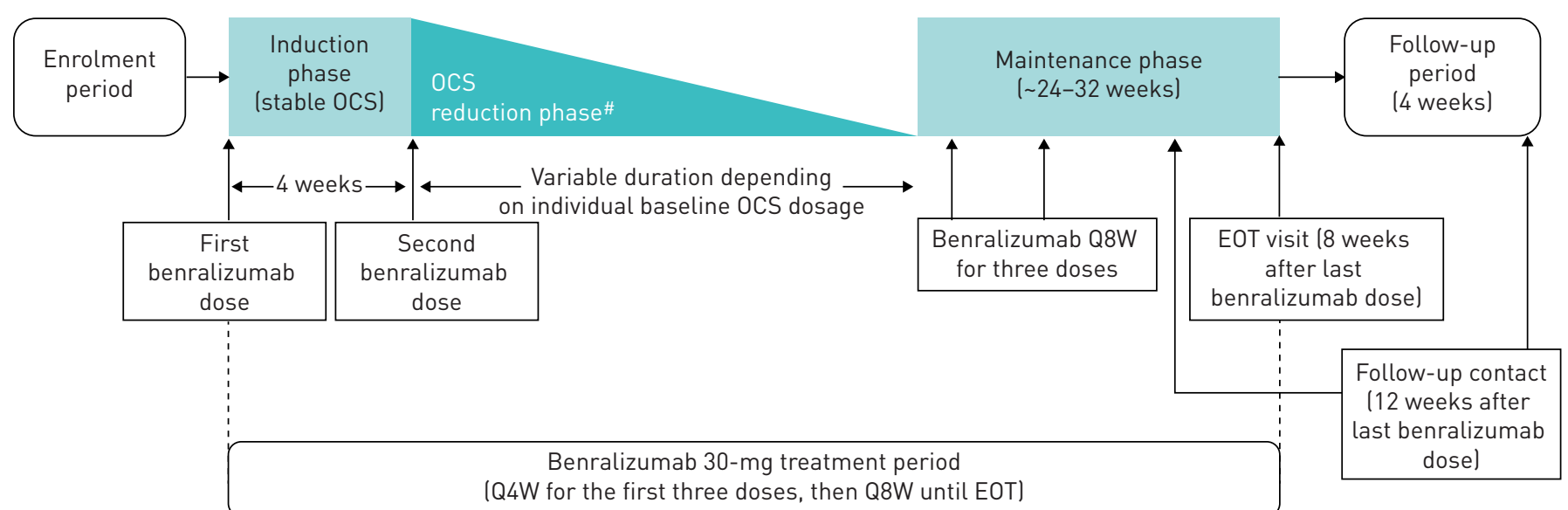

FIGURE 1 PONENTE study design. EOT: end of treatment; OCS: oral corticosteroid; Q4W: every 4 weeks; Q8W: every 8 weeks. ": guided by schema of OCS reduction defined in the study protocol.

of AI, as assessed by morning cortisol or ACTH stimulation test, OCS dose will be reduced by $2.5 \mathrm{mg}$ Q4W (figure 2). For those patients with partial AI or with symptoms suggestive of AI in the absence of abnormal AI tests, OCS tapering will follow a speed of $1 \mathrm{mg}$ Q4W. However, in case of complete AI, no further tapering in the OCS dosage will be allowed. Further OCS dosage reduction strategy will depend on results of the cortisol and ACTH tests. For patients with partial or complete AI, additional HPA axis integrity evaluations will be performed to monitor status.

Patients who completely withdraw OCS use or are maintained on the lowest OCS dosage possible without occurrence of AI or loss of asthma control will enter the maintenance phase, during which initiation or increase in OCS dosage is allowed in case of asthma worsening. A follow-up visit will be conducted 12 weeks after the last dose of benralizumab, discontinuation of benralizumab, or discontinuation from the study.

OCS tapering can be interrupted if patients experience asthma worsening or asthma exacerbation that requires increased OCS treatment ( $\geqslant 3$ consecutive days), hospitalisation, or emergency room admission. After completion of the OCS/bolus burst to treat an exacerbation, investigators can perform one of the following options for at least 2 weeks: 1) return patients to a one-step greater dosage (or more if

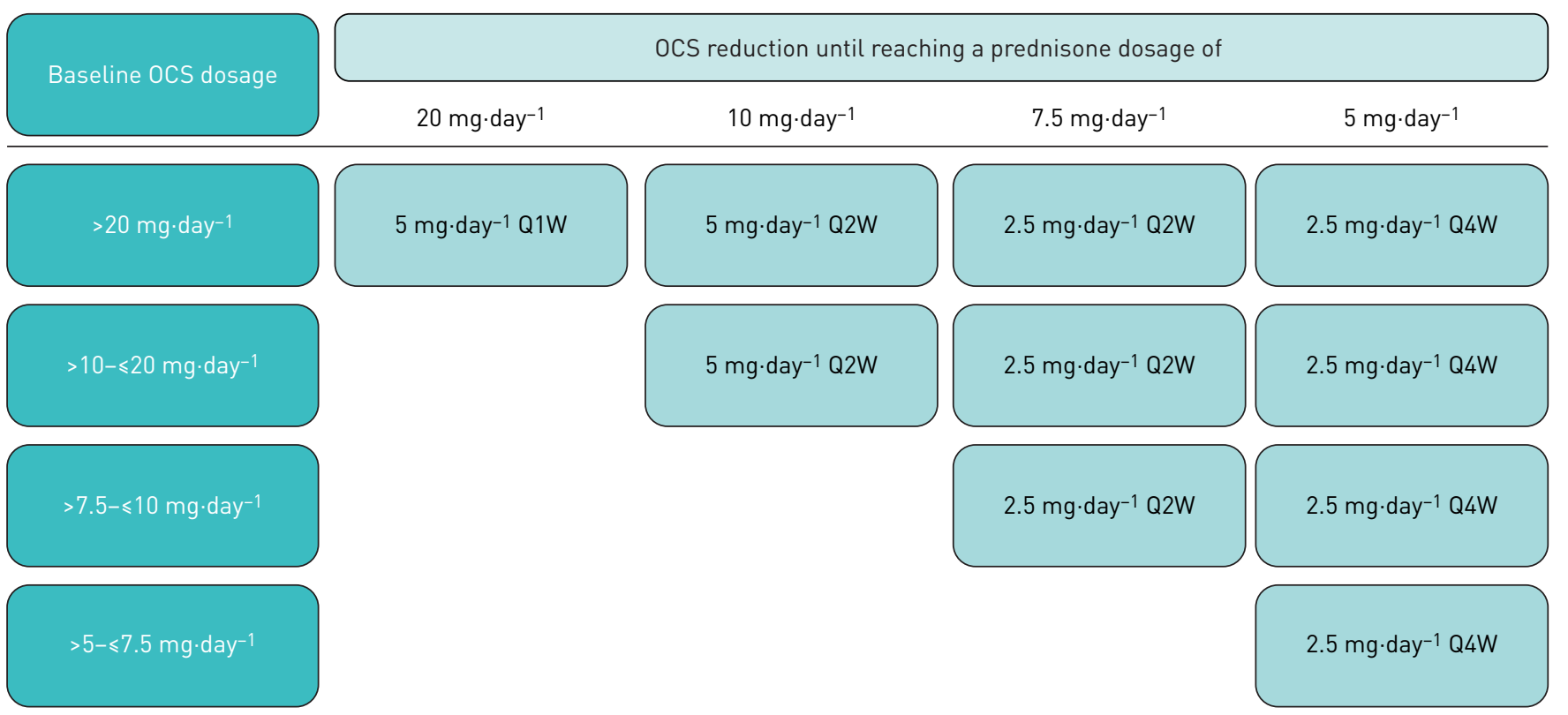

FIGURE 2 OCS down-titration schema until dosage of $5 \mathrm{mg} \cdot$ day $^{-1}$ is reached, without worsening of asthma. OCS: oral corticosteroid; Q1W: every week; Q2W: every 2 weeks; Q4W: every 4 weeks. 


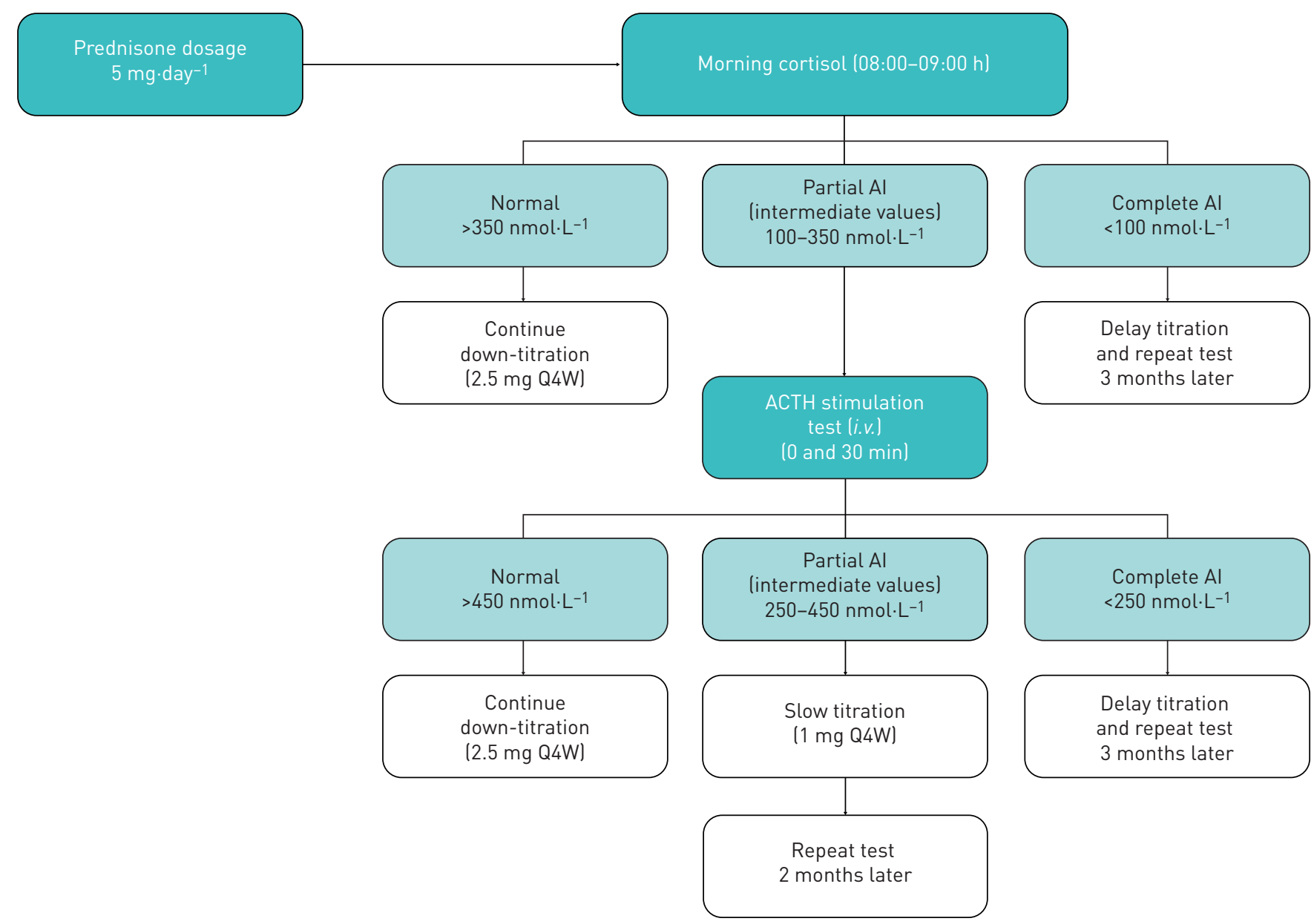

FIGURE 3 Hypothalamic-pituitary-adrenal axis evaluation and oral corticosteroid down-titration schema from prednisone dosage of 5 mg.day ${ }^{-1}$. ACTH: adrenocorticotropic hormone; Al: adrenal insufficiency; i.v.: intravenous; Q4W: every 4 weeks.

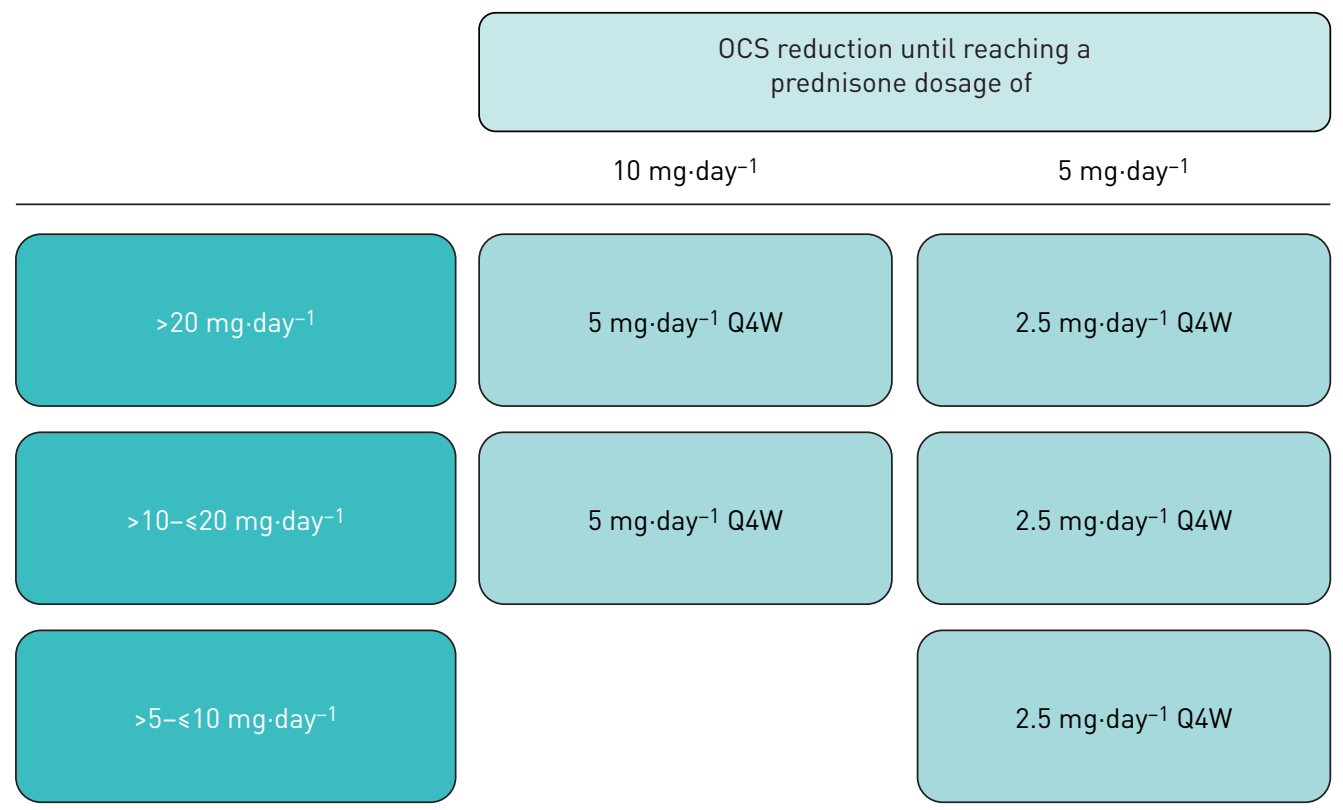

FIGURE 4 Rescue down-titration after recovery from asthma exacerbation or deterioration. OCS: oral corticosteroid; Q4W: every 4 weeks. 
considered necessary by the investigators) than was prescribed when the exacerbation occurred, or 2) maintain the patient on the same, stable OCS dosage before continuing OCS tapering upon recovery from the exacerbation.

Patients who have a first asthma exacerbation or asthma deterioration will be allowed to continue OCS reduction after recovery on a slower schedule, similar to the ZONDA trial design (Q4W), based on the investigators' judgement (figure 4). In the case of a second asthma exacerbation or worsening, OCS tapering will cease, and patients will continue their same dosages or return to a one-step greater dosage than what was prescribed when the exacerbation occurred.

The lowest OCS dosage that is stable during a 4-week period and prevents asthma exacerbation or asthma worsening without increasing OCS dosage will be considered the final OCS dosage of the OCS tapering phase. The patient will enter the maintenance phase with this dosage.

\section{Asthma control and health-related quality of life assessments}

ACQ-6 will be completed every week from the start of the induction phase (Week 0) to the end of treatment. Data will be collected via an electronic patient-reported outcomes device. ACQ-6 is scored on a scale from 0 to 6, with smaller numbers indicating better asthma control [19, 20]. St. George's Respiratory Questionnaire (SGRQ) will be completed at the start of the induction phase and at the end of treatment or discontinuation. SGRQ is scored on a scale from 0 to 100 , with greater scores indicating greater impairment $[21,22]$. Details of ACQ-6 and SGRQ are provided in the appendix.

\section{Safety assessments}

Safety will be monitored at each study centre from enrolment to the follow-up visit at the end of the study. Additionally, glucocorticoid toxicity index (GTI) will be measured at the induction phase, when patients achieve an OCS dosage of $\leqslant 5 \mathrm{mg} \cdot \mathrm{day}^{-1}$, and at the end of treatment or discontinuation [23]. The composite GTI measures common glucocorticoid toxicities that are sensitive to differing cumulative glucocorticoid dosages over a typical clinical trial period. Details of the GTI measurement are provided in the appendix.

\section{Outcome measures}

PONENTE has two primary efficacy endpoints. The first is whether patients achieve a $100 \%$ reduction in daily OCS dosage that is maintained for $\geqslant 4$ weeks without asthma worsening. The second is whether patients achieve $100 \%$ reduction in daily OCS dosage or a daily OCS dosage $\leqslant 5 \mathrm{mg}$, if the reason for no further OCS reduction is AI, that is maintained for $\geqslant 4$ weeks without asthma worsening.

Secondary efficacy endpoints are included to allow investigators to assess asthma control during the OCS tapering phase and the sustained reduction of daily OCS dosage while maintaining asthma control for approximately 6 months after the end of OCS tapering (maintenance phase) for patients treated with benralizumab. The effect of this treatment schedule on patients' asthma control and HRQOL will also be evaluated. Assessments will include additional measures of OCS reduction during both the OCS tapering and maintenance phases, and improvements in ACQ-6 and SGRQ scores. Exploratory outcomes will include the association of common and rare genomic variants and key blood/serum biomarker parameters with patients' response to treatment and OCS tapering, as well as change in baseline blood eosinophil counts during benralizumab treatment.

Safety outcomes will be the incidence of complete AI, annualised severe asthma exacerbation rate, annualised rate of severe asthma exacerbations leading to hospitalisation or emergency department visit, AEs, severe AEs, GTI, laboratory parameters and vital signs.

\section{Statistical analysis}

As there is no predefined hypothesis to statistically test in this study, the sample size is based on the ability to provide sufficient precision in point estimates, both in the full analysis set (FAS) and prespecified subpopulations. We estimate that a total sample size of 600 patients is required to provide sufficient precision. For the FAS, a sample size of 600 patients is expected to provide $95 \%$ confidence intervals (CI) extending $4.1 \%$ around the point estimate for a $50 \%$ observed success rate. For the primary outcome, the observed percentage of patients who successfully reduce OCS dosage, the expected success rate is $\geqslant 50 \%$. An interim review is included to re-assess the sample size.

Efficacy and safety analyses will be performed on the FAS, which will include all patients who received any dose of benralizumab. The study will be assessed descriptively. The Clopper-Pearson method will be used to determine the $\mathrm{CI}$ for the primary endpoints. 
TABLE 1 Comparison of PONENTE study features with published oral corticosteroid (OCS)-sparing studies of other biological treatments for severe asthma

\begin{tabular}{|c|c|c|c|c|c|c|c|}
\hline \multirow[t]{2}{*}{ Study name } & \multirow[t]{2}{*}{ Study type } & \multirow[t]{2}{*}{ Trial duration } & \multirow[t]{2}{*}{ Patients } & \multirow[t]{2}{*}{ Biologic } & \multirow[t]{2}{*}{ OCS inclusion criteria } & \multicolumn{2}{|r|}{ ocs tapering } \\
\hline & & & & & & Time frame & Dosage reduction \\
\hline $\begin{array}{l}\text { PONENTE } \\
\text { (ongoing) }\end{array}$ & $\begin{array}{l}\text { Open-label, } \\
\text { single-arm }\end{array}$ & $\begin{array}{l}>36 \text { weeks (variable } \\
\text { personalised OCS } \\
\text { tapering period) + } \\
4 \text { weeks follow-up }\end{array}$ & Aim: 600 & Benralizumab & $\begin{array}{l}\geqslant 5{\mathrm{mg} \cdot \text { day }^{-1} \text { of prednisone }}^{\text {(or equivalent) }}\end{array}$ & $\begin{array}{c}\text { Dose-reduction phase: } \\
\text { variable depending on } \\
\text { baseline OCS dosage } \\
\text { Maintenance phase: } \\
24-32 \text { weeks } \\
\text { Follow-up: } 4 \text { weeks } \\
\text { (Week 36) }\end{array}$ & $\begin{array}{l}\text { OCS dosages will be reduced by } 5 \mathrm{mg} \\
\text { either weekly or every } 2 \text { weeks or by } \\
2.5 \mathrm{mg} \text { every } 4 \text { weeks depending on } \\
\text { baseline OCS use/loss of asthma control } \\
\text { until reaching } \leqslant 5 \mathrm{mg} \cdot \text { day }^{-1} \\
\text { Following } 4 \text { weeks at } \leqslant 5 \mathrm{mg}^{-1} \text { day } \\
\text { further OCS reduction depends on } \\
\text { cortisol concentration and Al status } \\
\text { levaluated by HPA axis integrityl } \\
\text { assessed by ACTH stimulation testing }\end{array}$ \\
\hline ZONDA [18] & RCT & $\begin{array}{l}28 \text { weeks }+8 \text { weeks } \\
\text { follow-up }\end{array}$ & 220 & Benralizumab & 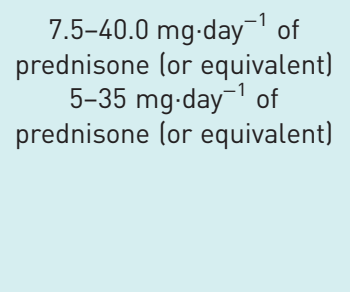 & $\begin{array}{c}\text { Dose-reduction phase: } \\
20 \text { weeks (Week 4-24) } \\
\text { Maintenance phase: } \\
4 \text { weeks } \\
\text { Follow-up: } 8 \text { weeks } \\
\text { (Week 36) }\end{array}$ & $\begin{array}{l}\text { OCS dosage reduced by } 2.5-5 \mathrm{mg} \cdot \text { day }^{-1} \\
\text { every } 4 \text { weeks luntil reaching a dosage of } \\
7.5 \mathrm{mg} \cdot \text { day }^{-1} \text {, then further reduced to } \\
5 \mathrm{mg} \cdot \text { day }^{-1}, 1.25 \mathrm{mg} \cdot \mathrm{day}^{-1} \text {, and } \\
0 \mathrm{mg} \cdot \text { day }^{-1} \text {; only patients with OCS } \\
\text { dosage of } \leqslant 12.5 \mathrm{mg} \cdot \text { day }^{-1} \text { at the end of } \\
\text { the run-in phase were eligible for a } 100 \% \\
\text { dose reduction) }\end{array}$ \\
\hline SIRIUS [28] & RCT & 24 weeks & 135 & Mepolizumab & $\begin{array}{l}5-35 \mathrm{mg} \cdot \mathrm{day}^{-1} \text { of } \\
\text { prednisone (or equivalent) }\end{array}$ & $\begin{array}{l}\text { Run-in optimisation } \\
\text { phase: } 3-8 \text { weeks } \\
\text { Dose-reduction phase: } \\
16 \text { weeks (Week 4-20) } \\
\text { Maintenance phase: } \\
4 \text { weeks (Week 24) }\end{array}$ & $\begin{array}{l}\text { Run-in OCS optimisation phase: OCS } \\
\text { reduced weekly until asthma worsening } \\
\text { Dose-reduction phase: OCS dosage } \\
\text { reduced by } 1.25-10 \mathrm{mg} \cdot d a y^{-1} \text { every } 4 \\
\text { weeks (based on asthma control and } \\
\text { symptoms of All; reduction only allowed } \\
\text { for patients with stable ACQ- } 5 \text { scores and } \\
\text { for whom the investigator deemed } \\
\text { appropriate }\end{array}$ \\
\hline VENTURE [29] & $\begin{array}{l}\text { International } \\
\text { RCT }\end{array}$ & 24 weeks & 210 & Dupilumab & $\begin{array}{l}5-35 \mathrm{mg} \cdot \mathrm{day}^{-1} \text { of } \\
\text { prednisone (or equivalent) }\end{array}$ & $\begin{array}{l}\text { Dose-reduction phase: } \\
16 \text { weeks (Week 4-20) } \\
\text { Maintenance phase: } \\
4 \text { weeks } \\
\text { Follow-up: } 12 \text { weeks }\end{array}$ & $\begin{array}{l}\text { OCS dosage reduced every } 4 \text { weeks } \\
\text { (protocol-specified algorithm; reduction } \\
\text { range } 2.5-25 \mathrm{mg}^{-1 y^{-1}} \text {, depending on } \\
\text { baseline OCS dosage); no dose } \\
\text { adjustments allowed after Week } 20\end{array}$ \\
\hline
\end{tabular}

RCT: randomised controlled trial; Al: adrenal insufficiency; HPA: hypothalamic-pituitary-adrenal; ACTH: adrenocorticotropic hormone; ACQ-5: five-item Asthma Control Questionnaire-5. 


\section{Discussion}

Systemic corticosteroids, usually in the form of OCS, have been the mainstay of treatment for severe asthma and asthma exacerbations for more than 50 years [20]. They continue to be used despite well-known related AEs and associated health care costs $[10,24]$. A United Kingdom study reported that $>90 \%$ of patients with severe asthma have at least one comorbidity associated with OCS use [25]. This contributes to an estimated $45 \%$ of patients who are non-adherent to prescribed OCS and therefore at risk of exacerbations in the absence of alternative prescriptions $[25,26]$. With the introduction of biologics for the treatment of asthma, there is an opportunity for less reliance and minimisation of long-term OCS use to prevent exacerbations [5].

Long-term OCS use can suppress the HPA axis, preventing endogenous cortisol production and leading to AI $[11,12]$. OCS-induced AI persists for 1 week after stopping OCS treatment for $26-49 \%$ of patients and can continue for months for some patients $[11,12]$. AI symptoms are non-specific and include fatigue and nausea, but they can also be fatal in physiologically stressful situations (e.g. surgery, bodily injury, or severe systemic infections). It is therefore important to monitor patients during OCS tapering, and up to 6 months following withdrawal from long-term OCS use, particularly once patients reach a physiological dosage (i.e. prednisone $5 \mathrm{mg} \cdot \mathrm{day}^{-1}$ ) [27]. Several targeted biologic therapies are now available for patients with severe and OCS-dependent asthma, but an established methodology for the safe tapering of OCS dosage following biologic initiation has yet to be confirmed.

The PONENTE study will investigate the potential for tapering the use of maintenance OCS following benralizumab initiation for patients with severe eosinophilic asthma who are OCS-dependent. The study design and future implementation are guided by an expert scientific committee that includes an endocrinologist. A protocol for OCS tapering, including reduction to less than the physiological dosage of prednisone $5 \mathrm{mg} \cdot \mathrm{day}^{-1}$ or equivalent, is included in the study design. A key element of the PONENTE study is the effectiveness of benralizumab for asthma control during rapid OCS tapering, while managing the signs and symptoms of AI. This will be determined primarily by the ability to completely withdraw OCS without worsening of asthma symptoms or to reach the lowest OCS dosage possible, if further OCS reduction is prevented by the presence of $\mathrm{AI}$ (as measured by cortisol concentrations) or in case of inadequate asthma control.

The PONENTE study has several advantages over previous studies on OCS reduction following the initiation of biologic therapy (table 1). Compared with published studies, PONENTE has a personalised OCS tapering schedule that allows for more rapid OCS tapering and depends on baseline OCS dosage and degree of asthma control. In addition, it contains a detailed safety methodology for AI monitoring during OCS reduction to $<5 \mathrm{mg} \cdot \mathrm{day}^{-1}$. It also has a significantly longer maintenance phase (approximately 24-34 weeks versus 4 weeks for published studies of other biologics), during which the efficacy and safety of benralizumab treatment following complete elimination of OCS (or lowest possible dosage, if AI prevented further reduction) will be evaluated comprehensively. Study limitations include the lack of a control group and an OCS adjustment phase.

With more widespread biologic use, it is important to have guidelines in place to ensure safe and effective OCS tapering after effective biologic therapy initiation. The PONENTE study will provide valuable guidance for clinicians on tapering OCS dosage, including how quickly OCS can be tapered and the management of AI, following benralizumab initiation for the treatment of OCS-dependent patients with severe, uncontrolled eosinophilic asthma. The results will aim to direct future clinical practice on OCS tapering following initiation of biologics and how to screen for and manage AI, thus potentially driving guideline changes.

Acknowledgements: Writing and editing assistance, including preparation of a draft manuscript under the direction and guidance of the authors, incorporating author feedback, and manuscript submission, was provided by Debra Scates of JK Associates, Inc. (Conshohocken, PA, USA) and Michael A. Nissen of AstraZeneca (Gaithersburg, MD, USA). This support was funded by AstraZeneca.

Conflict of interest: A. Menzies-Gow reports consultancy agreements with and advisory board membership for AstraZeneca, consultancy agreements with Sanofi and Vectura, advisory board membership for Boehringer Ingelheim, GlaxoSmithKline, Novartis, Sanofi and Teva, receiving speaker fees from AstraZeneca, Boehringer Ingelheim, Novartis, Teva and Vectura, clinical funding from AstraZeneca, having participated in research for which his institution was renumerated by AstraZeneca, and having attended international conferences with sponsorship from Teva and Boehringer Ingelheim, outside the submitted work. J. Corren has nothing to disclose. E.H. Bel reports grants for research and personal fees from AstraZeneca, Boehringer Ingelheim, GlaxoSmithKline, Novartis, Sanofi-Regeneron, Sterna, Teva, and Vectura. J. Maspero reports consultancy for Sanofi, Teva, Novartis and GlaxoSmithKline, speaker fees from Boehringer Ingelheim, AstraZeneca, Menarini, Novartis and Uriach, and research and grants from Sanofi, AstraZeneca and Novartis, outside the submitted work. L.G. Heaney has nothing to disclose. M. Gurnell has nothing to disclose P. Wessman is an employee of AstraZeneca. U.J. Martin is an employee of AstraZeneca. S. Siddiqui is an employee of AstraZeneca. E. Garcia Gil is an employee of AstraZeneca. 
Support statement: Funding for this study is provided by AstraZeneca. Funding information for this article has been deposited with the Crossref Funder registry.

\section{References}

1 Global Asthma Network. The global asthma report. www.globalasthmareport.org Date last accessed: November 21, 2018. Date last updated: 2018

2 To T, Stanojevic S, Moores G, et al. Global asthma prevalence in adults: findings from the cross-sectional world health survey. BMC Public Health 2012; 12: 204.

3 Global Initiative for Asthma Management and Prevention (GINA). Global strategy for asthma management and prevention. www.ginasthma.org/2018-gina-report-global-strategy-for-asthma-management-and-prevention Date last accessed: November 12, 2018. Date last updated: 2018.

4 Chung KF, Wenzel SE, Brozek JL, et al. International ERS/ATS guidelines on definition, evaluation and treatment of severe asthma. Eur Respir J 2014; 43: 343-373.

5 Menzies-Gow A, Canonica GW, Winders TA, et al. A charter to improve patient care in severe asthma. Adv Ther 2018; 35: 1485-1496.

6 Liu D, Ahmet A, Ward L, et al. A practical guide to the monitoring and management of the complications of systemic corticosteroid therapy. Allergy Asthma Clin Immunol 2013; 9: 30.

7 Moore WC, Bleecker ER, Curran-Everett D, et al. Characterization of the severe asthma phenotype by the National Heart, Lung, and Blood Institute's severe asthma research program. J Allergy Clin Immunol 2007; 119: 405-413.

8 Shaw DE, Sousa AR, Fowler SJ, et al. Clinical and inflammatory characteristics of the European U-BIOPRED adult severe asthma cohort. Eur Respir J 2015; 46: 1308-1321.

9 Price DB, Trudo F, Voorham J, et al. Adverse outcomes from initiation of systemic corticosteroids for asthma: long-term observational study. J Asthma Allergy 2018; 11: 193-204.

10 Voorham J, Xu X, Price D, et al. Health care resource utilization and costs associated with incremental systemic corticosteroid exposure in asthma. Allergy 2019; 74: 273-283.

11 Sweeney J, Patterson CC, Menzies-Gow A, et al. Comorbidity in severe asthma requiring systemic corticosteroid therapy: cross-sectional data from the Optimum Patient Care Research Database and the British Thoracic Difficult Asthma Registry. Thorax 2016; 71: 339-346.

12 Dinsen $\mathrm{S}$, Baslund $\mathrm{B}$, Klose $\mathrm{M}$, et al. Why glucocorticoid withdrawal may sometimes be as dangerous as the treatment itself. Eur J Intern Med 2013; 24: 714-720.

13 Kolbeck R, Kozhich A, Koike M, et al. MEDI-563, a humanized anti-IL-5 receptor alpha mAb with enhanced antibody-dependent cell-mediated cytotoxicity function. J Allergy Clin Immunol 2010; 125: 1344-1353.

14 Pham TH, Damera G, Newbold P, et al. Reductions in eosinophil biomarkers by benralizumab in patients with asthma. Respir Med 2016; 111: 21-29.

15 AstraZeneca. Fasenra ${ }^{\mathrm{TM}}$ (benralizumab). Prescribing information. www.azpicentral.com/fasenra/fasenra_pi.pdf Date last accessed: November 12, 2018. Date last updated: November 2017.

16 Bleecker ER, FitzGerald JM, Chanez P, et al. Efficacy and safety of benralizumab for patients with severe asthma uncontrolled with high-dosage inhaled corticosteroids and long-acting beta2-agonists (SIROCCO): a randomised, multicentre, placebo-controlled Phase 3 trial. Lancet 2016; 388: 2115-2127.

17 FitzGerald JM, Bleecker ER, Nair P, et al. Benralizumab, an anti-interleukin-5 receptor alpha monoclonal antibody, as add-on treatment for patients with severe, uncontrolled, eosinophilic asthma (CALIMA): a randomised, double-blind, placebo-controlled Phase 3 trial. Lancet 2016; 388: 2128-2141.

18 Nair P, Wenzel S, Rabe KF, et al. Oral glucocorticoid-sparing effect of benralizumab in severe asthma. $N$ Engl J Med 2017; 376: 2448-2458.

19 Juniper EF, Bousquet J, Abetz L, et al. Identifying "well-controlled" and "not well-controlled" asthma using the Asthma Control Questionnaire. Respir Med 2006; 100: 616-621.

20 Jia CE, Zhang HP, Lv Y, et al. The Asthma Control Test and Asthma Control Questionnaire for assessing asthma control: systematic review and meta-analysis. J Allergy Clin Immunol 2013; 131: 695-703.

21 Jones PW, Quirk FH, Baveystock CM. The St George's Respiratory Questionnaire. Respir Med 1991; 85: Suppl. B, 25-31; discussion 33-27.

22 Jones PW. St. George’s Respiratory Questionnaire: MCID. COPD 2005; 2: 75-79.

23 Miloslavsky EM, Naden RP, Bijlsma JW, et al. Development of a glucocorticoid toxicity index (GTI) using multicriteria decision analysis. Ann Rheum Dis 2017; 76: 543-546.

24 Ramsahai JM, Wark PAB. Appropriate use of oral corticosteroids for severe asthma. Med J Aust 2018; 209: Suppl. 2, S18-S21.

25 Asthma UK. Severe asthma: the unmet need and the global challenge; 2017. https://www.asthma.org.uk/ globalassets/get-involved/external-affairs-campaigns/publications/severe-asthma-report/auk_severeasthma_2017.pdf.

26 Gamble J, Stevenson M, McClean E, et al. The prevalence of nonadherence in difficult asthma. Am J Respir Crit Care Med 2009; 180: 817-822.

27 Alves C, Robazzi TC, Mendonca M. Withdrawal from glucocorticosteroid therapy: clinical practice recommendations. J Pediatr (Rio J) 2008; 84: 192-202.

28 Bel EH, Wenzel SE, Thompson PJ, et al. Oral glucocorticoid-sparing effect of mepolizumab in eosinophilic asthma. N Engl J Med 2014; 371: 1189-1197.

29 Rabe KF, Nair P, Brusselle G, et al. Efficacy and safety of dupilumab in glucocorticoid-dependent severe asthma. N Engl J Med 2018; 378: 2475-2485. 